\title{
Synthesis, crystal structure and phase transitions of a series of imidazolium iodides $\dagger$
}

Cite this: CrystEngComm, 2013, 15, 5633

Received 29th March 2013, Accepted 10th May 2013

DOI: 10.1039/c3ce40559a

www.rsc.org/crystengcomm

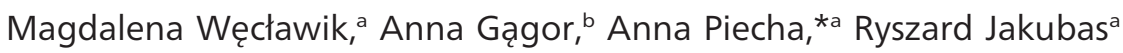 \\ and Wojciech Medyckic
}

\section{Introduction}

Ionic liquids based on various substituted imidazolium salts are characterized by low melting points, many of them are liquid at room temperature. Extensive studies of ionic liquids have revealed a great number of useful properties such as extremely low volatility, high thermal stability and high ionic conductivity. ${ }^{1-4}$ Therefore, the above-mentioned ionic liquids have found application in solar cells, electrochemical devices and ion transport systems. ${ }^{5}$

Bulky plane organic cations like non-substituted imidazolium are widely used in numerous organic-inorganic hybrids. Such organic molecules play a role of simple dielectric rotator units which have been used to obtain new ferroelectric materials. The known representatives of this group of ferroic compounds are based on haloantimonates(III) and halobismuthates(III) with the $\mathrm{R}_{5} \mathrm{M}_{2} \mathrm{X}_{11}$ chemical stoichiometry (where $\mathrm{R}=$ imidazolium cation $\left(\mathrm{C}_{3} \mathrm{~N}_{2} \mathrm{H}_{5}^{+}\right), \mathrm{M}=\mathrm{Sb}, \mathrm{Bi}$ and $\mathrm{X}=$

${ }^{a}$ Faculty of Chemistry, University of Wrocław, F. Joliot-Curie 14, 50-383 Wrocław, Poland. E-mail: anna.piecha@chem.uni.wroc.pl; Fax:+48713757270;

Tel: +48713757288

${ }^{b}$ W. Trzebiatowski Institute of Low Temperature and Structure Research PAS, P. O. Box 1410, 50-950 Wroctaw, Poland

'Institute of Molecular Physics, PAS, M. Smoluchowskiego 17, 60-179 Poznań, Poland $\dagger$ Electronic supplementary information (ESI) available: Details of the thermal (TGA), X-ray diffraction and dielectric and ${ }^{1} \mathrm{H}$ NMR measurements. CCDC 929449-929453. For ESI and crystallographic data in CIF or other electronic format see DOI: 10.1039/c3ce40559a
$\mathrm{Cl}, \mathrm{Br}$ ). Three imidazolium ferroelectrics with this composition have already been synthesized and characterized. ${ }^{6-8}$ The 'order-disorder' mechanism of ferroelectric transition in $\mathrm{R}_{5} \mathrm{M}_{2} \mathrm{X}_{11}$ type compounds was assigned to the dynamics of imidazolium cations. Very recently, bis(imidazolium) L-tartrate, a hydrogen-bonded 'displacive' type ferroelectric material was discovered. ${ }^{9}$ The simple $(1: 1)$ ionic complexes of imidazolium and tetrahedral anions were found to also exhibit ferroelectric properties at the room temperature phases; $\left[\mathrm{C}_{3} \mathrm{~N}_{2} \mathrm{H}_{5}{ }^{+}\right]\left[\mathrm{ClO}_{4}{ }^{-}\right]^{10}$ and $\left[\mathrm{C}_{3} \mathrm{~N}_{2} \mathrm{H}_{5}{ }^{+}\right]\left[\mathrm{BF}_{4}{ }^{-}\right] \cdot{ }^{11}$

Imidazolium analogs in which the anionic network is formed by the halogen atoms appeared to be the simplest as regards the crystal structure; however, they have been studied only fragmentarily. Recently, we have characterized the molecular-ionic compound, $\left[\mathrm{C}_{3} \mathrm{~N}_{2} \mathrm{H}_{5}{ }^{+}\right]\left[\mathrm{Br}^{-}\right]$(ImBr), which shows very interesting structural and dynamic properties. ${ }^{12}$ The crystal structure of the RT phase is described by the polar, $R 3$ space group and consists of a highly disordered imidazolium cations and discrete $\mathrm{Br}^{-}$anions. ImBr reveals a first order phase transition at 199/201 K (cooling-heating cycle) which leads to the monoclinic centrosymmetric space group $P 2_{1} / m$. The mechanism of the phase transition is mixed; related to the freezing of cation motions ('order-disorder' ('o-d') contribution) and to a significant rebuilding of the anionic substructure ('displacive' ('d')-type mechanism).

The aim of this paper is to present details of physicochemical properties of a series of imidazolium salts; $\left[\mathrm{C}_{3} \mathrm{~N}_{2} \mathrm{H}_{5}{ }^{+}\right]\left[\mathrm{I}^{-}\right]$ 
(1) and $\left[\mathrm{C}_{3} \mathrm{~N}_{2} \mathrm{H}_{5}{ }^{+}\right]_{2}\left[\mathrm{I}_{4}{ }^{2-}\right]$ (3) including preparation, crystal structures in various phases, thermal and dielectric properties. Structural characterization is presented also for a new substituted imidazolium compound; $\left[\mathrm{C}_{3} \mathrm{~N}_{2} \mathrm{H}_{3} \mathrm{I}_{2}{ }^{+}\right]\left[\mathrm{I}^{-}\right]$(2). The molecular motions in (1) and (3) are studied by means of proton magnetic resonance measurements $\left({ }^{1} \mathrm{H}\right.$ NMR) (for more information, see ESI†). The molecular mechanism of the phase transitions in the crystals under investigation is also proposed.

\section{Experimental section}

\section{Materials and instrument}

Synthesis of the complexes. All compounds were obtained in the reaction between imidazole amine and iodic acid, however, both synthesis-reactions were carried out in different conditions (temperature and molar ratio) applied for each compound.

(1) crystals were prepared at ambient temperature by dissolving imidazole in the $20 \%$ HI solution. Single crystals were grown by slow evaporation from the solution. The crystalline product was twice recrystallized. Single transparent crystals were grown by slow evaporation from an aqueous solution and characterized by an elemental analysis: C: $18.37 \%$ (theor. $18.39 \%$ ), N: $14.25 \%$ (theor. $14.29 \%$ ), H $2.49 \%$ (theor. $2.57 \%)$.

(2) crystals were prepared by dissolving imidazole in the $20 \%$ HI solution. Subsequently, the mixture was stirred (at 320 $\mathrm{K}$ for about $30 \mathrm{~min})$. After a few days, tiny minuscule transparent solids were formed by a slow evaporation from the colorless solution. Nevertheless, due to small amounts of obtained material (only X-ray diffraction measurements were undertaken) we were not able to make the physicochemical characterization of this material. We obtained successfully the 4,5-diiodoimidazolium iodide crystals only during the first crystallization. The following crystallization produced exclusively the (1) crystals.

(3) crystals were prepared at ambient temperature by dissolving imidazole in concentrated (57\%) HI. Single crystals were grown by slow evaporation from the solution. The dark, navy blue, needle like crystals were characterized by an elemental analysis: C: $11.18 \%$ (theor. $11.16 \%$ ), N: $8.55 \%$ (theor. 8.68\%), H 1.59\% (theor. 1.56\%).

\section{General details}

All the solvents and starting materials for the synthesis were purchased commercially and were used as received.

DSC traces were obtained using a Perkin Elmer model 8500 differential scanning calorimeter calibrated using $n$-heptane and indium. Hermetically sealed Al pans with the polycrystalline material were prepared in a controlled-atmosphere $\mathrm{N}_{2}$ glovebox. The measurements were performed between 100 and $470 \mathrm{~K}$. The thermal hysteresis was estimated from the scans performed at various rates $\left(20,10\right.$ and $\left.5 \mathrm{~K} \mathrm{~min}^{-1}\right)$ extrapolated to a scanning rate of $0 \quad \mathrm{~K} \mathrm{~min}^{-1}$. Simultaneous Thermogravimetric Analysis (TGA) and Differential Thermal Analysis (DTA) were performed on a Setaram SETSYS 16/18 instrument in the temperature range $300-700 \mathrm{~K}$ with a ramp rate $2 \mathrm{~K} \mathrm{~min}^{-1}$ the scans was performed in flowing nitrogen (flow rate: $1 \mathrm{dm}^{3} \mathrm{~h}^{-1}$ ).

The complex electric permittivity, $\varepsilon^{*}=\varepsilon^{\prime}-i \varepsilon^{\prime \prime}$ was measured between 100 and $290 \mathrm{~K}$ by the Agilent E4980A Precision LCR Meter in the frequency range between $135 \mathrm{~Hz}$ and $2 \mathrm{MHz}$. The overall error was less than $5 \%$. The single crystal samples had dimensions $c a .2 \times 2 \times 0.5 \mathrm{~mm}^{3}$. Silver electrodes were printed on opposite faces. The dielectric measurements were carried in a controlled atmosphere $\left(\mathrm{N}_{2}\right)$.

Single crystal X-ray diffraction crystallographic data were collected on a KM4 diffractometer with CCD detector and graphite-monochromated Mo K $\alpha$ radiation $(\lambda=0.71073 \AA)$. Low temperature was maintained using an open flow unit (Oxford Cryosystem). The CrysAlis software version 1.171.32 was used for data processing. ${ }^{13}$ An empirical absorption correction was applied using spherical harmonics implemented in SCALE3 ABSPACK scaling algorithm. The structure was solved by direct methods and refined against $F^{2}$ by means of SHELX-97 program package. ${ }^{14}$ All non-hydrogen atoms were refined anisotropically. $\mathrm{H}$ atoms were included in geometric positions and treated as riding atoms. The $U_{\text {iso }}(H)$ were constrained to be $x U_{\text {eq }}$ (carrier atom), where $x=1.2$.

Structural phase transitions observed with temperature lowering led to twinning of the (1) and (3) crystals. In (3) symmetry changed from orthorhombic to monoclinic which resulted in crystal twinning with two dominating domains, with partially overlapped diffraction peaks. Refinement of the structure was performed using the data from both domains and HKLF 5 instruction.

In the case of (1) two structural transformations were encountered. During the cooling cycle the crystal symmetry changed from trigonal to triclinic (at $180 \mathrm{~K}$ ) and with further cooling to a monoclinic one (113/123 K cooling-heating). Lowering of the crystal class led to non-merohedral twinning of the sample. Six triclinic crystal domains were encountered at $150 \mathrm{~K}$ from the splitting of diffraction peaks. Partial overlapping of the peaks together with weak intensities did not allow satisfactory indexing, thus the crystal structure of this intermediate phase has not been determined. Below $113 \mathrm{~K}$ the symmetry of (1) increased to monoclinic and the number of domains was reduced to three. The structure refinement was based on the diffraction intensities from one dominating crystal domain, indexing $60 \%$ of the measured diffraction peaks. All peaks were completely separated. Table 1 contains crystal data and structure refinement results of measured crystals.

\section{Results and discussion}

\section{Thermal properties}

The DSC runs of (1) (Fig. 1(a)) revealed two PTs at 180/185 K and 113/123 K (cooling-heating) of the first order type. The PTs are reversible, however, the enthalpy effects differ on cooling and heating significantly. The entropy values were estimated to be $c a .7 \mathrm{~J} \mathrm{~mol}^{-1} \mathrm{~K}^{-1}$ for the I $\leftrightarrow$ II PT and $2 \mathrm{~J}$ 
Table 1 Crystal data and structure refinement results for $\left[\mathrm{C}_{3} \mathrm{~N}_{2} \mathrm{H}_{5}{ }^{+}\right]\left[\mathrm{I}^{-}\right](\mathbf{1}),\left[\mathrm{C}_{3} \mathrm{~N}_{2} \mathrm{H}_{3} \mathrm{I}_{2}^{+}\right]\left[\mathrm{I}^{-}\right](2)$ and $\left[\mathrm{C}_{3} \mathrm{~N}_{2} \mathrm{H}_{5}{ }^{+}\right]_{2}\left[\mathrm{I}_{4}{ }^{2-}\right](\mathbf{3})$

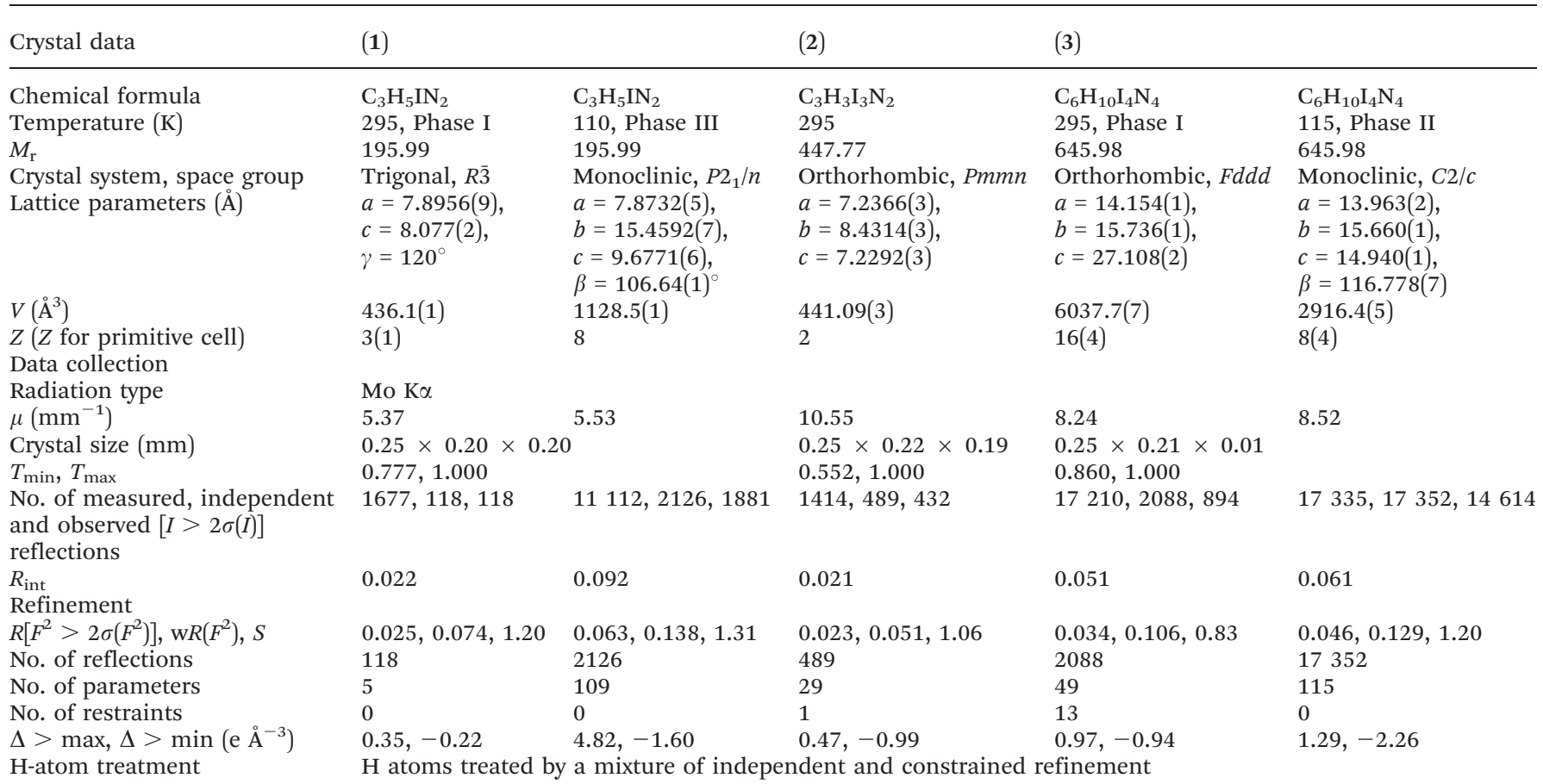

$\mathrm{mol}^{-1} \mathrm{~K}^{-1}$ for the II $\leftrightarrow$ III one (the heating cycle) and are characteristic of the ' $\mathrm{O}-\mathrm{d}$ ' mechanism of phase transition.

A complex sequence of PTs is also encountered in (3) (Fig. 1(b)). For the cooling cycle only one heat anomaly characteristic of the second order transition is revealed at $c a$. $204 \mathrm{~K}$, whereas on heating two thermal anomalies are seen; at $136 \mathrm{~K}$ typical of the first order type and another one at higher temperature corresponding to the PT detected on cooling at $204 \mathrm{~K}$. The presence of a lower temperature heat anomaly may suggest the possibility of existence of a metastable phase below $204 \mathrm{~K}$.

The sequence of the PTs observed in the calorimetric measurements (DSC) for (1) and (3) is in a good agreement

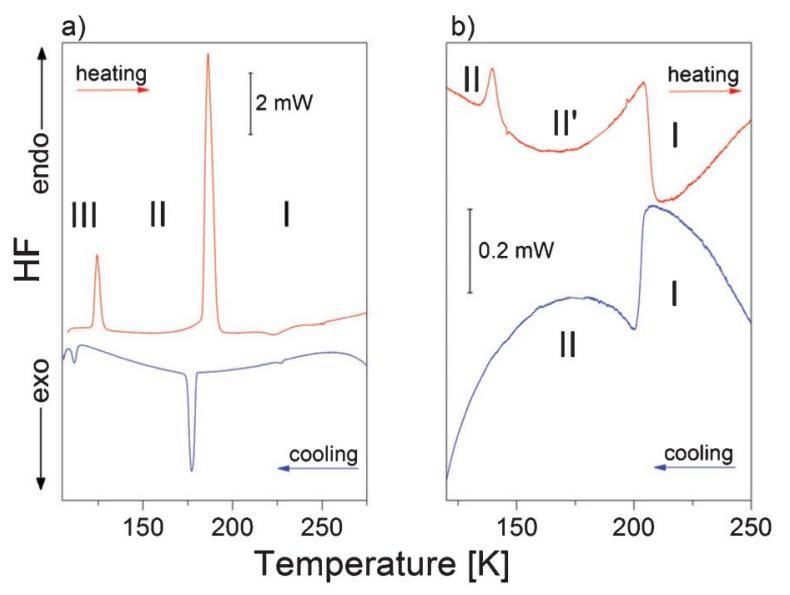

Fig. 1 DSC curves for (a) (1) (b) (3) upon cooling and heating runs ( $2 \mathrm{~K} \mathrm{~min}^{-1}$, (a) $m=20.8 \mathrm{mg}$, (b) $m=21.2 \mathrm{mg}$ ). with the linear thermal expansion measurements. Both compounds are stable up to $c a .500 \mathrm{~K}$, however, above this temperature a continuous decomposition takes place (see Fig. $\mathrm{S} 1(\mathrm{a})$ and $\mathrm{S} 1(\mathrm{~b})$ in ESI $\dagger$ ).

\section{Structure discussion}

The crystal structure of (1) (Phase I). (1) crystallizes in the trigonal system in the centrosymmetric $R \overline{3}$ space group. $\mathrm{I}^{-}$ ions occupy all corners of the unit cell as well as two positions on the $[-111]$ diagonal whereas imidazolium cations are located in the middle of the line connecting two adjacent anions in the $c$ direction. The packing is similar to those reported for $\mathbf{I m B r}$ (ref. 12) although these two simple structures are not isomorphic. (1) adopts higher symmetry compared to $\mathrm{Br}^{-}$analog $(R \overline{3}$ vs. $R 3)$ and reveals a much more complicated disorder of the counterions.

$\left[\mathrm{C}_{3} \mathrm{~N}_{2} \mathrm{H}_{5}{ }^{+}\right]$are disordered over a three-fold axis adopting 6 possible orientations. High values of displacement parameters of anions together with an unstable position of imidazolium cations indicate a low stability of the trigonal structure. Thermal motions dominate over possible directional bonding down to $180 \mathrm{~K}$. Below this point, a drastic symmetry lowering occurs and the crystal structure transforms to triclinic in the first order phase transition. All cell parameters show discrete changes that are much pronounced for the angles and the $b_{\text {mono }}$ direction (Fig. S2, ESI $\dagger$ ). The transition from Phase I to II is accompanied by a crystal expansion in the $b_{\text {mono }}$ direction by about $2.3 \%$ and a slight contraction of $a_{\text {mono }}$ and $c_{\text {mono }}$ axes; the most pronounced changes are observed for all unit cell angles that deviate greatly from $90^{\circ}$ indicating a triclinic symmetry of Phase II.

The lack of any anomalies of pyroelectric current in the vicinity of the $180 \mathrm{~K}$ temperature points to the centrosym- 


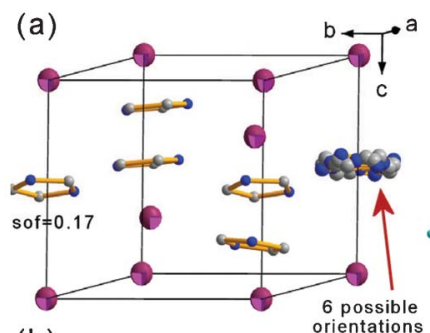

(b)

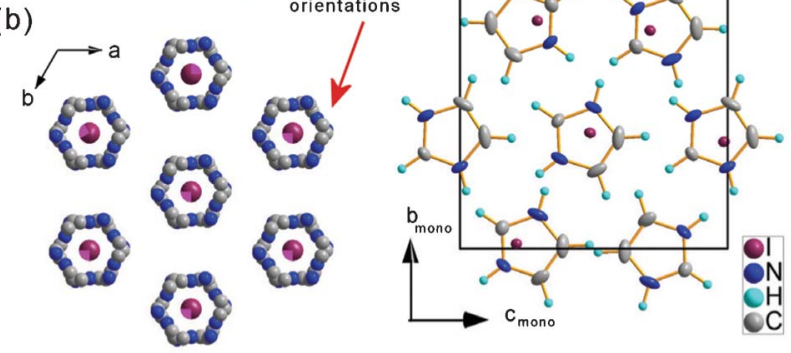

Fig. 2 Crystal structure of (1) (a) and (b) trigonal Phase I with disordered imidazolium counterions, six possible orientations of imidazolium are possible in $R \overline{3}$ symmetry, selected positions with the site occupation factor equal to 0.17 are presented as well as the averaged picture, $T=295 \mathrm{~K}$, (c) Phase III with ordered, pseudo-hexagonal arrangement of ions, $T=110 \mathrm{~K}$.

metric space group, $P \overline{1}$, for Phase II. The intermediate, triclinic phase is preserved down to $113 \mathrm{~K}$. Then, the crystal symmetry increases to the monoclinic one, $P 2_{1} / n$ (Phase III). Both phase transitions have a clear first-order character, there is no group-subgroup relation between the phases and translation symmetry also changes distinctively.

The crystal structure of (1) (Phase III). The unit cell periodicity is not preserved during the transformation from I to III Phase. The volume of the unit cell changes from $436 \AA^{3}$ at $295 \mathrm{~K}$ to $1128 \AA^{3}$ at $110 \mathrm{~K}$. The monoclinic lattice parameters are equal to $a_{\text {mono }}=7.8732(5) \AA, b_{\text {mono }}=15.4592(7) \AA, c_{\text {mono }}=$ 9.6771(6) $\AA, \beta=106.64(1)^{\circ}$. The asymmetric unit contains two independent tetraiodide anions and two imidazolium counterions. Fig. 2 presents the crystal packing in Phase I (a, b) and III (c) showing an hexagonal arrangement of ions in Phase I and pseudo-hexagonal arrangement of imidazolium counterions and $\mathrm{I}^{-}$anions in Phase III.

Phase transitions affect both the imidazolium cations that are stabilized in the low temperature structure and positions of the anions that shift from 'trigonal' sites distinctively. The phase transitions are thus of a mixed character possessing both ' $\mathrm{o}-\mathrm{d}$ ' and ' $\mathrm{d}$ ' contributions. The local symmetry of the cation stays the same in all phases whereas the high $\overline{3} m$ symmetry site of $\mathrm{I}^{-}$in Phase I lowers to 1 in Phase III. The reorientation motions of imidazolium cations are frozen in Phase III, the arrangement of the ions is established due to the weak $\mathrm{N}-\mathrm{H} \cdots \mathrm{I}$ interactions. The low temperature phase is composed of two non-equivalent chains of $\mathrm{I}^{-}-\left[\mathrm{C}_{3} \mathrm{~N}_{2} \mathrm{H}_{5}{ }^{+}\right]-\mathrm{I}^{-}$ propagating perpendicular to each other within the adjacent planes.

Fig. 3 presents the hydrogen-bonded chains propagating in the $b$ and $c$ directions. The geometry of the hydrogen bonds is given in Table 2. The $\mathrm{I}^{-}$anions exhibit large shifts from their high temperature positions. The I-I distance shrinks in $c_{\text {hex }}$

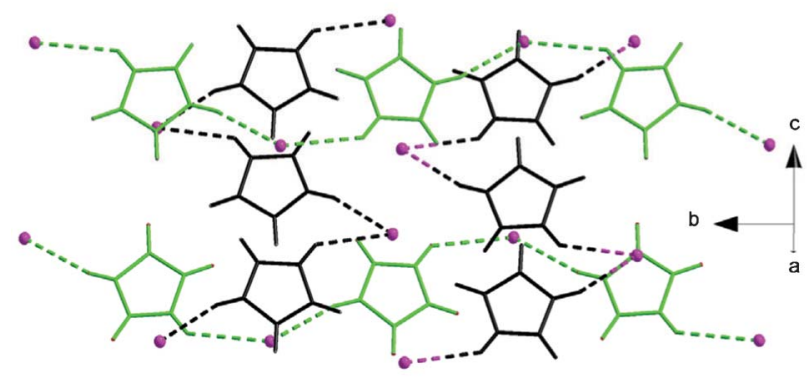

Fig. 3 Hydrogen bonded chains of $\mathrm{I}^{-}-\left[\mathrm{C}_{3} \mathrm{~N}_{2} \mathrm{H}_{5}{ }^{+}\right]-\mathrm{I}^{-}$in Phase III, $T=110 \mathrm{~K}$.

Table 2 Selected hydrogen-bond parameters in (1) at $110 \mathrm{~K}$, Phase $1 \mathrm{II}^{\mathrm{a}}$

\begin{tabular}{lllll}
\hline $\mathrm{D}-\mathrm{H} \cdots \mathrm{A}$ & $\mathrm{D}-\mathrm{H} / \AA$ & $\mathrm{H} \cdots \mathrm{A} / \AA$ & $\mathrm{D} \cdots \mathrm{A} / \mathrm{A}$ & $\mathrm{D}-\mathrm{H} \cdots \mathrm{A}\left({ }^{\circ}\right)$ \\
\hline $\mathrm{N} 1-\mathrm{H} 1 \cdots \mathrm{I} 2$ & 0.86 & 2.91 & $3.591(8)$ & 136.9 \\
$\mathrm{~N} 3-\mathrm{H} 3 \cdots \mathrm{I} 2{ }^{\mathrm{i}}$ & 0.86 & 2.75 & $3.533(8)$ & 151.5 \\
$\mathrm{~N}^{\circ}-\mathrm{H} 6 \cdots \mathrm{I} 1$ & 0.86 & 2.83 & $3.551(8)$ & 143.1 \\
$\mathrm{~N}^{2}-\mathrm{H} 8 \cdots \mathrm{I} 1{ }^{\mathrm{ii}}$ & 0.86 & 2.83 & $3.525(8)$ & 139.6
\end{tabular}

${ }^{a}$ Symmetry code(s): (i) $-x+1 / 2, y-1 / 2,-z+3 / 2$; (ii) $x-1 / 2,-y+$ $1 / 2, z-1 / 2$.

direction from 8.08(1) $\AA$ at $295 \mathrm{~K}$ to $7.87(2) \AA$ at $110 \mathrm{~K}$ that results in contraction of the $a_{\text {mono }}$ lattice parameter whereas shifts of anions in hexagonal (001) plane are at the origin of a pronounced increase of the $b_{\text {mono }}$ parameter.

The crystal structure of (2). The crystal structure of (2) is built of planes in which moieties are held together by $\mathrm{I} \cdots \mathrm{I}$ halogen and $\mathrm{N}-\mathrm{H} \cdots \mathrm{I}$ hydrogen bonds (see Fig. 4).

The distance between the planes is equal to 3.618(1) $\AA$. In the plane, each diiodoimidazolium is involved in two hydrogen and two halogen bonds. $\mathrm{I}^{-}$acts as an acceptor in these four interactions.

(a)

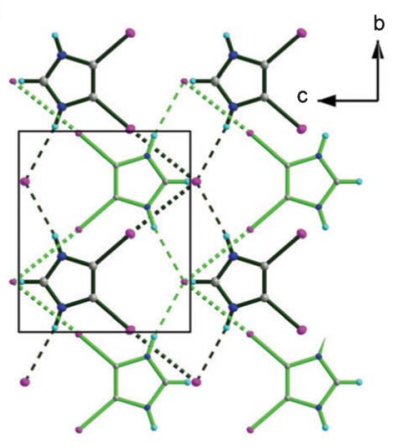

(b)

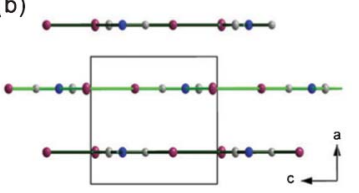

(c)

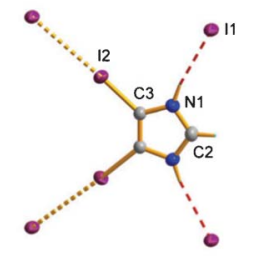

Fig. 4 Crystal structure of (2) (a) view along a direction, the crystal is composed of layers with halogen and hydrogen bonds as motif-defining interactions, green bonds - top layer, black bonds - down layer, dense dashed lines stand for halogen $\mathrm{I}-\mathrm{I}$ bonds, thicker ones represent $\mathrm{N}-\mathrm{H} \cdots \mathrm{I}$ interactions. (b) View along the $b$ direction, the interlayer spacing is equal to $3.62 \AA$ (c) model of interactions between 4,5-diiodoimidazolium and iodide, the atoms from the asymmetric unit are labeled. 
Table $3|\cdots|$ and $\mathrm{I}-\mathrm{I}$ distances in $\left[\mathrm{I}_{4}{ }^{2-}\right]$ complexes $^{a}$

\begin{tabular}{|c|c|c|c|c|}
\hline Phenancetin $\cdot \mathrm{H}_{2} \mathrm{I}_{4} \cdot 2 \mathrm{H}_{2} \mathrm{O}$ & 3.403 & 2.773 & 3.403 & 19 \\
\hline$\left(\mathrm{C}_{10} \mathrm{H}_{14} \mathrm{~N}_{4} \mathrm{Se}_{2}\right)\left(\mathrm{I}_{3}\right)\left(\mathrm{I}_{4}\right)_{0.5}$ & 3.405 & 2.819 & 3.405 & 20 \\
\hline$\left[\mathrm{Co}\left(\mathrm{OSMe}_{2}\right)_{6}\right] \mathrm{I}_{4}$ & 3.338 & 2.845 & 3.338 & 22 \\
\hline$\left[\mathrm{V}(\mathrm{MeCN})_{6}\right] \mathrm{I}_{4}$ & 3.166 & 2.846 & 3.516 & 23 \\
\hline$\alpha-(\mathbf{1}) \cdot 3 \mathrm{HI} \cdot \mathrm{I}_{2}$ & 3.201 & 2.792 & 3.547 & 24 \\
\hline \multirow{7}{*}{$\begin{array}{l}\text { (Pentafluorobenzyldibenzyl-a } \\
1,3 \text {-Bis(diphenylpentafluoro-b } \\
\left.\left[2\{\text { tHPMT })_{2}{ }^{2+}\right\}\left(2 \mathrm{I}^{-}\right) \cdot\left(\mathrm{I}_{4}{ }^{2-}\right)\right]^{b} \\
\left.\left.\left[2\{\mathrm{PMTH})_{2}{ }^{+}\right\} \cdot\left(\mathrm{I}_{4}{ }^{2-}\right)\right]\right]^{c^{c}} \\
\mathrm{BTMAH}^{2+} \cdot \mathrm{I}_{4}{ }^{2-d} \\
\text { (3) Phase I, orthorhombic } \\
\text { (3) Phase III, monoclinic }\end{array}$} & 3.362 & 2.792 & 3.418 & \\
\hline & 3.363 & 2.762 & 3.363 & 17 \\
\hline & 3.403 & 2.826 & 3.403 & 17 \\
\hline & 3.360 & 2.825 & 3.360 & 25 \\
\hline & 3.346 & 2.761 & 3.346 & 25 \\
\hline & 3.440 & 2.829 & 3.440 & 26. \\
\hline & 3.415 & 2.811 & 3.415 & This work \\
\hline
\end{tabular}

Both bonds are considerably strong although the geometrical parameters indicate that halogen bonds predominate hydrogen interactions. The I-I distance of 3.5410(1) $\AA$ is significantly shorter then the sum of the van der Waals radii $(4.12 \AA)$, and the angle $\theta_{1}$ that is equal to $177.6^{\circ}$ gives almost a linear configuration. The $\mathrm{I} \cdots \mathrm{N}$ distance is equal to 3.505(5) $\AA$ in $\mathrm{N}(1)-\mathrm{H}(1) \cdots \mathrm{I}(1)$ bond and donor-to-acceptor angle equals $170(7)^{\circ}$. The basic hydrogen and halogen bonded pattern is a ten membered ring. The asymmetric unit contains half of the diiodoimidazolium counter ion, laying on a $m$ lattice plane and being intersected by a $m$ mirror plane and 2 axis, and one $\mathrm{I}^{-}$anion adopting $\mathrm{mm} 2$ symmetry site. The exceptional feature of this simple salt is the layered crystal structure that has not been observed in other dihalogenoimidazolium salts and its derivatives. It is formed probably as a consequence of halogen-halogen interactions. These interactions are important packing forces in brominated hydroxyimidazoles. ${ }^{15}$

The crystal structure of (3). The anionic substructure of (3) comprises a rare and exotic $\left[\mathrm{I}_{4}{ }^{2-}\right]$ tetraiodide dianion that may be treated as a charge-transfer complex of two donating iodide anions and an accepting iodine molecule. ${ }^{16}$ Electrostatic repulsion between the two iodide anions bound to a central diiodine moiety implies low stability of the anion. Although $\left[\mathrm{I}_{4}{ }^{2-}\right]$ species has been observed in some complexes (see Table 3) the (3) is a rare example of a crystal in which very weak hydrogen bond interactions stabilize the anionic substructure and lead to the phase transformation that change the symmetry of $\left[\mathrm{I}_{4}{ }^{2-}\right]$ dianion.

The room temperature structure is disordered. The asymmetric unit comprises one-half of $\left[\mathrm{I}_{4}{ }^{2-}\right]$ dianion, one imidazolium with occupancy 0.5 and two one-half imidazolium cations with occupancy 0.5 , see Fig. 5 (a) and (b).

The bonds $\mathrm{I}-\mathrm{I}_{\text {terminal }}$ are equivalent and equal to $3.415 \AA$, the internal I-I bond is equal to $2.811 \AA$. The terminal iodides are weakly bonded to iodine molecule. Similar distances to terminal iodides in other crystals are shorter, e.g. $3.363 \AA$ in 1,3-bis(diphenylpentafluorobenzylphosphonium)propane salts. $^{17}$

$\left[\mathrm{I}_{4}{ }^{2-}\right]$ tetraiodide dianions and imidazolium counterions stack along one direction giving pseudo-hexagonal crystal packing. Fig. 5(c) shows the arrangement of ions at $295 \mathrm{~K}$. Imidazolium cations, distributed in large channels, are able to perform thermally activated librations and rotations in and out of the plane of the rings.

The rings are almost perpendicular to the iodide rods. Despite the fact that two $\mathrm{NH}$ groups are in a bonding distance to $\left[\mathrm{I}_{4}{ }^{2-}\right]$ the $\mathrm{H}$-bonds are not strong enough to overcome thermally activated motions. Thus the possible hydrogen bonds have a dynamical character. Below $204 \mathrm{~K}$ directional

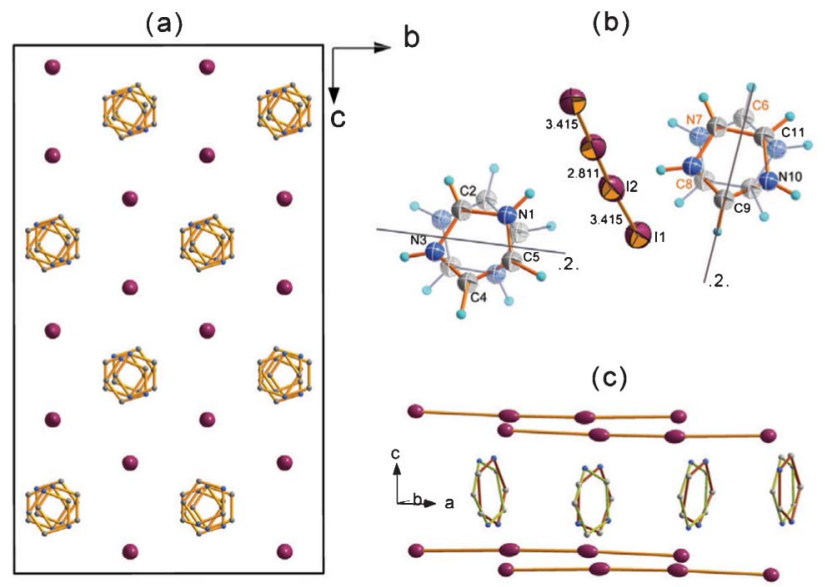

Fig. 5 Crystal structure of (3) in Phase I, $T=295 \mathrm{~K}$ (a) pseudo-hexagonal arrangement of ions along the a direction (b) model of disorder of imidazolium counterions together with the structure of $\left[\mathrm{I}_{4}{ }^{2-}\right]$ dianion, site occupation factor for each imidazolium position equals 0.5; atoms from asymmetric unit are labeled, double symmetry axis (.2.) are marked (c) arrangement of counterions in respect to $\left[\mathrm{I}_{4}{ }^{2-}\right]$ rods, hydrogen atoms are omitted for the clarity. 
bonding starts dominating over thermal motions that stands at the origin of a second-order phase transition. Due to this transformation the symmetry changes from orthorhombic Fddd to monoclinic $C 2 / c(C 2 / c$ is a maximal non-isomorphic subgroup of $F d d d$ ). The phase transition is group-subgroup related, the crystal class changes from $\mathrm{mmm}$ to $2 / \mathrm{m}$. According to the Aizu classification (3) belongs to the ferroelastic species $\mathrm{mmmF2} / \mathrm{m}^{18}$ In both phases of (3) the size of the primitive cells coincides and the number of $\mathrm{C}_{6} \mathrm{H}_{10} \mathrm{I}_{4} \mathrm{~N}_{4}$ formal molecules in primitive cells $(Z)$ is equal to 4 . Fig. S3, ESI, $\dagger$ presents the thermal evolution of the lattice parameters. Deformation of the crystal structure is much pronounced in the direction of the iodide rods and stacking imidazolium counter ions. Observed temperature changes have continuous character. Phase transition is associated with ordering of the cationic substructure and deformation of the $\left[\mathrm{I}_{4}{ }^{2-}\right]$ dianions that lose their symmetrical arrangement. The internal distance between iodides remains almost identical as in the high temperature phase whereas distances between $\mathrm{I}-\mathrm{I}_{\text {terminal }}$ change significantly from $3.43 \AA$ in Phase I to $3.51 \AA$ and $3.21 \AA$ in Phase II.

Independent content of the unit cell consists now of three, fully occupied imidazolium positions $\mathrm{A}, \mathrm{B}$ and $\mathrm{C}$ and four iodides forming a highly asymmetric $\left[\mathrm{I}_{4}{ }^{2-}\right]$ dianion, see Fig. 6 . In Phase II imidazolium rings are not perpendicular to the iodide rods, they bend aside approx. $12^{\circ}$ from the initial positions. H-bond interactions stabilize three different spatial orientations of imidazolium ions in the crystal structure.

A basic hydrogen bonded pattern consists of two iodide rods interconnected via a counterion by two symmetrical N(6)$\mathrm{H}(6) \cdots \mathrm{I}(1)$ bonds with a donor-to-acceptor distance of $3.52 \AA$ and two imidazolium cations type B interacting via $\mathrm{N}(1)-$ $\mathrm{H}(1) \cdots \mathrm{I}(2)$ with terminal iodides with the distance of $3.61 \AA$. Imidazolium $\mathrm{C}$ does not interact by hydrogen bonds with the rods. Fig. 6 shows the structure of hydrogen bonds in Phase II.

To the best of our knowledge there are only twelve crystal structures containing discrete polyiodide $\left[\mathrm{I}_{4}{ }^{2-}\right]$ moieties. The $\left[\mathrm{I}_{4}{ }^{2-}\right]$ species may be described as an $\mathrm{I}_{2}$ molecule bound to two $\mathrm{I}^{-}$ions through linear halogen bonding that is the intermolecular interaction involving the halogen atoms as electrophilic species with the central I-I bond length ranging from 2.76 and $2.85 \AA$ and the external $\mathrm{I}-\mathrm{I} \cdots \mathrm{I}^{-}$distances ranging from $c a .3 .17$ to $3.55 \AA$.

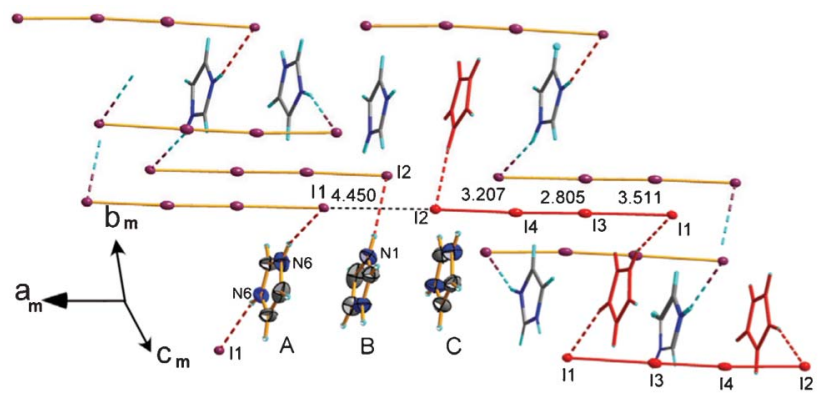

Fig. 6 Arrangement of counterions in respect to $\left[\mathrm{I}_{4}{ }^{2-}\right]$ rods in Phase II. Dashed lines represent hydrogen bond interactions. Hydrogen bonded motif is marked on red. Independent imidazolium ions are labeled with A, B and C.

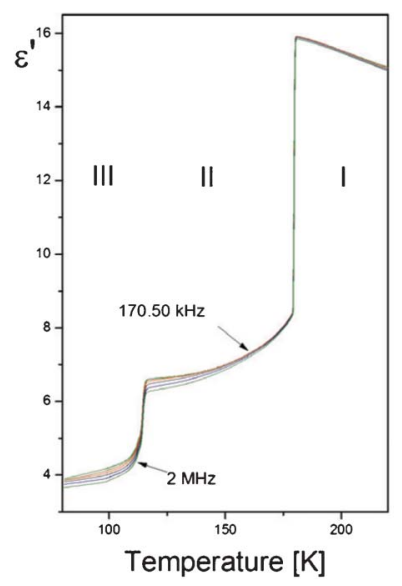

Fig. 7 Temperature dependence of the real part of the complex electric permittivity along the [ $\left.\begin{array}{lll}\overline{1} & 1 & 1\end{array}\right]$ direction for (1) during the cooling cycle.

Despite the fact that the linear $\left[\mathrm{I}_{4}{ }^{2-}\right]$ ion has been found to be unstable, nine of twelve compounds possess symmetrical configuration at room temperature. The present work is a first report on the temperature stability of the $\left[\mathrm{I}_{4}{ }^{2-}\right]$ rods.

Electrical properties of (1) and (3). Fig. 7 shows temperature dependence of the real part of the complex electric permittivity $\left(\varepsilon^{*}\right)$ measured between $170 \mathrm{kHz}$ and $2 \mathrm{MHz}$ for a single-crystal sample of (1) along the [ [ $\left.\begin{array}{lll}1 & 1 & 1\end{array}\right]$ direction, in the temperature region covering the two low temperature PTs. Both PTs are dielectrically active. The low frequency dielectric response possesses interesting features which are encountered both in antiferroelectric compounds and crystals possessing high temperature plastic-like phases. When the temperature approaches $180 \mathrm{~K}_{\varepsilon}^{\prime}{ }_{\mathrm{c}}$ increases linearly up to 16 units and below $180 \mathrm{~K}$ it suddenly drops to 8 units. A similar behavior of $\varepsilon^{\prime}(T)$ is observed in the vicinity of the II $\rightarrow$ III PT, however, the reduction of $\varepsilon^{\prime}$ is smaller, $c a .25 \%$.

Dielectric dispersion is not observed both in the high and low temperature phase. It means that the possible motion of the dipolar groups should be relatively fast in the disordered Phase I and II.

It is interesting to compare dynamic properties of closely related halogen analogs: ImBr (ref. 12) and (1), taking into account their sequence of PTs presented in Fig. 8.

The common feature of the RT Phases I of both compounds is a high dynamic disorder of the imidazolium cations. The low temperature PTs are governed by a change in the motions of dipoles of imidazole rings. The completely freezing of these motions in the case of $\mathbf{I m B r}$ takes place exactly at $199 \mathrm{~K}$, whereas in (1) a two-stage freezing was observed at 180 and

\begin{tabular}{ccc}
$P 2_{1} / \mathrm{m}(\mathrm{II})$ & $R 3(\mathrm{I})$ \\
\hline & $P \overline{1}(\mathrm{II})$ & $R 9 / 201 \mathrm{~K}(\mathrm{C} / \mathrm{H})$ \\
\hline $113 / 135 \mathrm{~K}(\mathrm{C} / \mathrm{H})$ & $180 / 185 \mathrm{~K}(\mathrm{C} / \mathrm{H})$
\end{tabular}

Fig. 8 Sequence of PTs for $\mathrm{ImBr}$ and (1) (C-cooling, H-heating). 


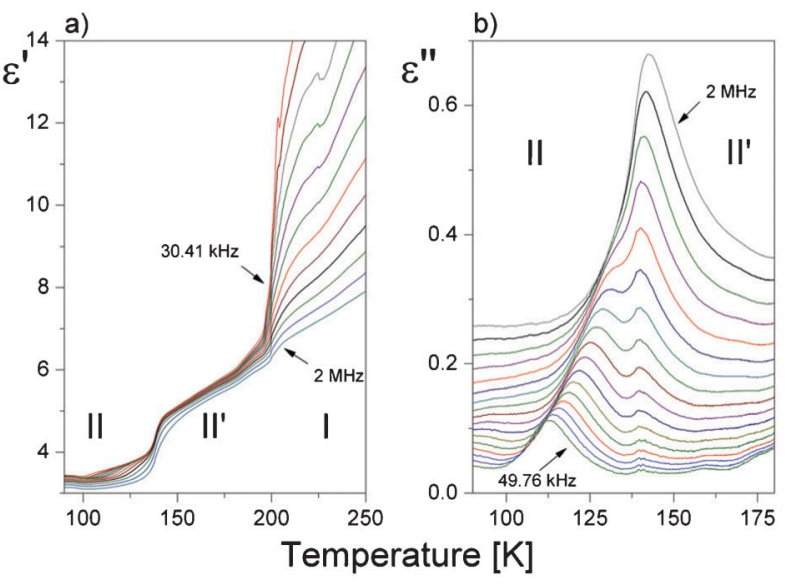

Fig. 9 Temperature dependence of the (a) real and (b) imaginary part of the complex electric permittivity along the [231] direction for (3) during the heating cycle.

$113 \mathrm{~K}$. The total entropy transition effect $\left(\Delta S_{\mathrm{tr}}\right)$ for (1) corresponds to a three-site model describing the cations disorder in Phase I.

Compared compounds adopt different symmetries at the RT phase: ImBr has polar space group $(R 3)$ while (1) a centrosymmetric one $(R \overline{3})$. In general, the electric response of both analogs in the vicinity of I $\rightarrow$ II PT reveals some similarities (e.g. the shape of $\varepsilon v s$. T), however, in the case of $\operatorname{ImBr}$ the $\varepsilon_{\text {max }}\left(T_{\mathrm{c}}\right)$ is nearly three times larger than that in (1). As for ImBr the polar character of the Phase I results from two contributions; permanent electric dipole of organic cations $\left(\Delta P^{\prime}\right)$ and dipoles arising from mutual positions of the centre of gravity of the $\mathrm{C}_{3} \mathrm{~N}_{2} \mathrm{H}_{5}{ }^{+}$cations and $\mathrm{Br}^{-}$anions along the $c$-axis $(\Delta P)$. In the case of $(\mathbf{1})$ we deal only with the $\left(\Delta P^{\prime}\right)$ contribution of the cations which justifies the lower $\varepsilon^{\prime}$ value over the Phase I.

The temperature dependence of real $\left(\varepsilon^{\prime}\right)$ and imaginary $\left(\varepsilon^{\prime \prime}\right)$ parts of the complex electric permittivity for (3) along the [ [ $\left.\begin{array}{lll}2 & 3 & 1\end{array}\right]$ direction (on heating) is presented in Fig. 9(a) and (b), respectively. The expected PTs at 136 and $204 \mathrm{~K}$ are visible as a rapid increase in the $\varepsilon^{\prime}$ value. In the low temperature region over the Phases II and III one can observe a relaxation process which is characteristic of the glass-like phases, where the value of $\varepsilon^{\prime \prime}{ }_{\text {max }}$ increases with the frequency of the measuring electric field.

The activation energy for the temperature region 110-140 K was found to be ca. $17 \mathrm{~kJ} \mathrm{~mol}^{-1}$ (see Fig. S4 and S5, ESI $\dagger$ ). Concluding, the dielectric relaxation process taking place below room temperature in (3) is due to a freezing and slowing down motion of dipolar units assigned to the imidazolium cations.

The molecular mechanism of PTs in (3) seems also to be complex and associated with an ordering of the cationic moieties and a significant deformation of the $\left[\mathrm{I}_{4}{ }^{2-}\right]$ dianions

\section{Conclusion}

The reaction between imidazole amine and hydroiodic acid in an aqueous solution results in simultaneous crystallization of three molecular-ionic compounds: $\quad\left[\mathrm{C}_{3} \mathrm{~N}_{2} \mathrm{H}_{5}^{+}\right]\left[\mathrm{I}^{-}\right] \quad$ (1), $\left[\mathrm{C}_{3} \mathrm{~N}_{2} \mathrm{H}_{3} \mathrm{I}_{2}{ }^{+}\right]\left[\mathrm{I}^{-}\right]$(2) and $\left[\mathrm{C}_{3} \mathrm{~N}_{2} \mathrm{H}_{5}{ }^{+}\right]_{2}\left[\mathrm{I}_{4}{ }^{2-}\right]$ (3). The crystal structure of all the compounds consisted of isolated discrete imidazolium cations and simple iodide anions, however, in the case of (3) we have a rarely encountered polyiodide form $\left[\mathrm{I}_{4}{ }^{2-}\right]$. The characteristic feature of compounds under investigation is the presence of $\mathrm{N} \cdots \mathrm{H}-\mathrm{I}$ hydrogen bonds and $\mathrm{I} \cdots \mathrm{I}$ halogen interactions. As a result a two-dimensional (2D) framework structure of (2) and (3) complexes is generated, whereas in (1) a 1D structure, as $\mathrm{I}^{-}-\left[\mathrm{C}_{3} \mathrm{~N}_{2} \mathrm{H}_{5}^{+}\right]-\mathrm{I}^{-}$chains, is observed. The structure of (2) appeared to be very rigid since the $\mathrm{I}^{-}$anion interacts with four atoms (via $\mathrm{N}-\mathrm{H} \cdots \mathrm{I}$ and $\mathrm{I} \cdots \mathrm{I}$ ). It is an exceptional feature because such a layered crystal structure is not observed in other dihalogenoimidazolium derivatives.

Two complexes were found to undergo reversible PTs; (1) at ca. 180/185 $\mathrm{K}$ and $113 / 123 \mathrm{~K}$ (cooling-heating) and (3) at ca. $204 \mathrm{~K}$ and $136 \mathrm{~K}$.

The X-ray, thermal, ${ }^{1} \mathrm{H}$ NMR and dielectric studies used to study the molecular mechanism of the PTs in (1) and (3) indicated a mixed molecular mechanism ('o-d' and ' $\mathrm{d}$ ' contributions). It should be emphasized that (3) is the first example of an ionic salt among all of the known compounds (12) containing polyiodide anions, $\left[\mathrm{I}_{4}{ }^{2-}\right]$, which undergo structural PTs. The most unexpected in this case is the fact that the instability of the crystal structure of (3) at $204 \mathrm{~K}$ is governed by the distortion of an unstable, symmetric $\left[\mathrm{I}_{4}{ }^{2-}\right]$ species.

The proton spin-lattice relaxation time (T1) measurements confirmed that a free in-plane reorientation of the imidazolium ring takes place over the high temperature phase of (1) and (3) whereas large-amplitude librations or small-angle reorientations of cations are permitted at low temperatures (Phases II and III).

\section{Notes and references}

1 P. Wasserscheid and T. Welton, Ionic Liquids in Synthesis, Wiley-VCH, Weinheim, 2003.

2 J. Dupont, R. F. de Souza and P. A. Suarez, Chem. Rev., 2002, 102, 3667.

3 C. E. Song, Chem. Commun., 2004, 1033.

$4 \mathrm{H}$. Ohno, Electrochemical Aspect of Ionic Liquids, WileyInterscience, 2005.

$5 \mathrm{H}$. Ohno, Electrochemical Aspect of Ionic Liquids, WileyInterscience, in particular Part V and VI, ch. 24-27, 2005.

6 R. Jakubas, A. Piecha, A. Pietraszko and G. Bator, Phys. Rev. $B, 2005$, B72, 104107.

7 A. Piecha, A. Białońska and R. Jakubas, J. Phys.: Condens. Matter, 2008, 20, 325224.

8 A. Piecha, A. Pietraszko, G. Bator and R. Jakubas, J. Solid State Chem., 2008, 181, 1155.

9 Z. Sun, T. Chen, J. Luo and M. Hong, Angew. Chem., Int. Ed., 2012, 51, 3871.

10 Z. Pająk, P. Czarnecki, B. Szafrańska, H. Małuszyńska and Z. Fojud, J. Chem. Phys., 2006, 124, 144502. 
11 Z. Pająk, P. Czarnecki, B. Szafrańska, H. Małuszyńska and Z. Fojud, Phys. Rev. B, 2004, B69, 132102.

12 A. Gągor, A. Piecha, R. Jakubas and A. Miniewicz, Chem. Phys. Lett., 2011, 503, 134.

13 Oxford Diffraction, CrysAlis CCD, Data Collection software, Oxford Diffraction Ltd., Wrocław, Poland, 2005.

14 G. M. Sheldrick, Acta Crystallogr., Sect. A: Found. Crystallogr., 2007, A64, 112-122.

15 G. Laus, K. Wurst, V. Kahlenberg and H. Schottenberger, Z. Naturforsch., B: J. Chem. Sci., 2012, 67, 354.

16 O. Hassel, Mol. Phys., 1958, 1, 241.

17 M. Muller, M. Albrecht, V. Gossen, T. Peters, A. Hoffmann, G. Raabe, A. Valkonen and K. Rissanen, Chem.-Eur. J., 2010, 16, 12446.

18 K. Aizu, J. Phys. Soc. Jpn., 1969, 27, 387.

19 F. H. Herbstein, M. Kapon and W. Schwotzer, Helv. Chim. Acta, 1983, 66, 35.
20 F. Bigoli, F. Demartin, P. Deplano, F. A. Devillanova, F. Isaia, V. Lippolis, M. L. Mercuri, M. A. Pellinghelli and E. F. Trogu, Inorg. Chem., 1996, 3683.

21 D. L. Long, H. M. Hu, J. T. Chen and J. S. Huang, Acta Crystallogr., Sect. C: Cryst. Struct. Commun., 1999, 55, 339.

22 V. V. Tkachev, E. A. Lavrenteva, O. S. Roshchupkina, I. P. Lavrentev and L. Y. Atovmyan, Koord. Khim., 1994, 20, 674.

23 P. B. Hitchcock, D. L. Hughes, G. J. Leigh, J. R. Sanders, J. Desouza, C. J. McGarry and L. F. Larkworthy, J. Chem. Soc., Dalton Trans., 1994, 3683.

24 C. A. Ilioudis and J. W. Steed, CrystEngComm, 2004, 6, 239-242.

25 A. M. Owczarzak, M. Kubicki, N. Kourkoumelis and S. K. Hadjikakou, RSC Adv., 2012, 2, 2856.

26 A. Abate, M. Brischetto, G. Cavallo, M. Lahtinen, P. Metrangolo, T. Pilati, S. Radice, G. Resnati, K. Rissanen and G. Terraneo, Chem. Commun., 2010, 46, 2724 . 